\title{
Language-Related Field Potentials in the Anterior-Medial Temporal Lobe: Il. Effects of Word Type and Semantic Priming
}

\author{
Anna C. Nobrea and Gregory McCarthy \\ Neuropsychology Laboratory, VA Medical Center, West Haven, Connecticut 06516, and Section of Neurosurgery, Yale \\ University School of Medicine, New Haven, Connecticut 06510
}

Field potentials were recorded from intracranial electrodes in humans to study the role of the anterior medial temporal lobe (AMTL) in language-related processing. Subjects viewed lists of words in which orthography and word type varied, or in which words were primed by semantic associates. Large negative field potentials were elicited within the AMTL by isolated words. The amplitude and intracranial distribution of these AMTL field potentials were consistent with those in our previous study in which anomalous sentence-ending words were used as stimuli (McCarthy et al., in press). The neocortex, in the region of the collateral sulcus and anterior fusiform gyrus, was identified as the likely neural generator of this field potential. The AMTL field potential was diminished by semantic priming, and was larger for words with semantic content than for words serving grammatical function. Orthographically illegal nonwords did not elicit this field potential. The N400 scalp event-related potential (ERP) has been shown to respond in the same manner to these task manipulations (Nobre and McCarthy, 1994), and, thus, the AMTL field potential was proposed to contribute to the generation of N400. The possible roles in language processing reflected by the AMTL field potential were considered.

In the preceding article we showed that the anterior medial temporal lobe (AMTL) was involved in the processing of words by recording event-related field potentials (ERPs) from intracranial electrodes (McCarthy ct al., 1995). Wc demonstratcd that a field potential termed the AMTL N400 was elicited by semantically anomalous sentence-ending words. On the basis of its intracranial distribution, we concluded that the AMTL N400 was generated in and near the collateral sulcus and fusiform gyrus. Words that were congruous with the sentence context did not elicit this potential. In the present study, we sought to explore the nature of the language-related processes reflected by the AMTL N400 by using word-list tasks in which orthography, word type, and semantic priming were varied. These manipulations have been shown previously to affect the am-

\footnotetext{
Received Mar. 22, 1994; revised June 23, 1994; accepted July 6, 1994.
}

We thank Dr. Truett Allison, Dr. Marsel Mesulam, and two anonymous reviewers for constructive criticisms of the manuscript. Kevin McCarthy, Elizabeth Roessler, and Marie Luby provided technical assistance. Support for this research was provided by the Department of Veteran's Affairs and by NIMH Grant MH05286.

Correspondence should be addressed to Gregory McCarthy, Ph.D., Neuropsychology Laboratory 116B1, VA Medical Center, West Haven, CT 06516.

- Present address: Department of Experimental Psychology, Oxford University, South Parks Road, Oxford OX1 3UD UK.

Copyright (C) 1995 Society for Neuroscience $0270-6474 / 95 / 151090-09 \$ 05.00 / 0$ plitude of the N400 ERP recorded noninvasively from scalp electrodes (Nobre and McCarthy, 1994).

Scalp-recorded N400s have been identified in many different tasks using sentences and word lists. N400 is elicited by language-related stimuli (e.g., Kutas and Hillyard, 1980; Besson and McCar, 1986, 1987; Rugg and Nagy, 1987; Paller et al., 1992) in both auditory and visual modalities (e.g., McCallum et al., 1984; Kutas et al., 1987). The amplitude of N400 is attenuated by semantic priming in sentences (e.g., Kutas et al., 1984; Fischler et al., 1985; Holcomb and Neville, 1991; Van Petten and Kutas, 1991; Kounios and Holcomb, 1992) and in word lists (Bentin et al., 1985; Rugg, 1985; Boddy, 1986; Holcomb, 1986), and is modulated by selective attention (McCarthy and Nobre, 1993) and depth of stimulus processing (Bentin, 1987; Holcomb, 1988; Kutas and Hillyard, 1989). It has been proposed that $\mathrm{N} 400$ reflects access to the lexical or semantic representation of a word (Kutas and Van Petten, 1988; Fischler and Raney, 1989), or postlexical processes, such as associative processes that integrate word representations with ongoing context (Rugg and Doyle, 1992; Holcomb, 1993).

In the present study, we demonstrate that isolated words elicit an AMTL N400, and that its amplitude is sensitive to word orthography and word type. We further demonstrate that the amplitude of the AMTL N400 is reduced when the eliciting word has been preceded by a semantic associate. These results are similar to those obtained for the scalp-recorded N400, suggesting that scalp-recorded N400 may bc, in part, a volumcconducted representation of AMTL activity. Hypotheses regarding the nature of neural processing reflected by the AMTL $\mathrm{N} 400$ are discussed, as well as the contribution of this field potential in the generation of N400 recorded from scalp sites.

\section{Materials and Methods}

\section{Subjects}

Ten patients with intracranial electrodes placed in the temporal lobe were studied. All were patients in the Yale-West Haven VAMC epilepsy surgery program who were being evaluated as candidates for surgical intervention to treat medically intractable seizures. Their mean age was 27.7 years and their verbal IQ averaged 89.2. Nine of the patients were right-handed. As part of patient evaluation, intracranial multicontact depth probes and subdural strip electrodes were chronically implanted to localize their seizure focus or foci. Experimental recordings were obtained concurrently with continuous EEG monitoring 3-10 d following implant surgery. The experimental nature of the tasks was explained to each patient, and informed consent was obtained. The protocols used in this study were approved by the Yale and VAMC Human Investigations Committees.

\section{Experimental tasks}

Two language tasks were used, both of which had been previously used to elicit N400 ERP from scalp recordings (Nobre and McCarthy, 1994). 
TASK 1: WORDS AND NONWORDS

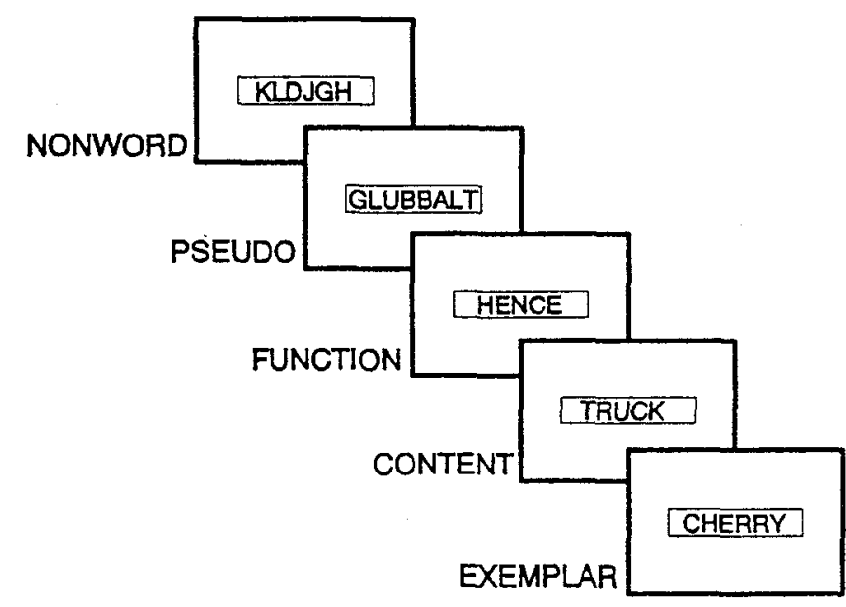

TASK 2: SEMANTIC PRIMING

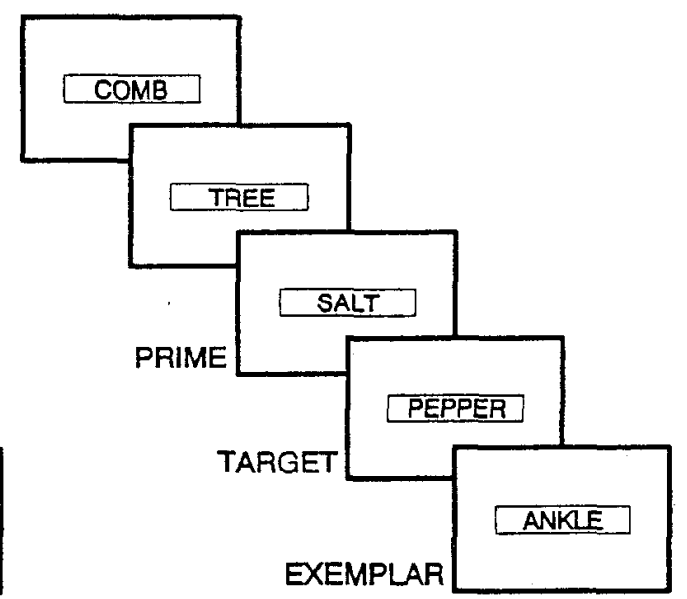

Figure 1. Left: words and nonwords experimental task. Strings of letters were presented individually and foveally within an illuminated horizontal rectangle. Stimulus duration was $500 \mathrm{msec}$ and stimulus onset asynchrony (SOA) ranged from 2100 to $2200 \mathrm{msec}$. The subject was asked to press a response key as accurately and rapidly as possible when an exemplar of the category of "fruits and vegetables" appeared. The stimuli were presented in random order across subjects and consisted of orthographically illegal NONwORDs; orthographically legal PSEUDo words; words that serve grammatical FUNCTION; concrete nouns, which have semantic CONTENT; and category EXEMPLARs. Right: semantic priming task. Concrete nouns were presented individually and foveally within an illuminated horizontal rectangle, with the same parameters used for the words-nonwords task. The subject was asked to press a response key as accurately and rapidly as possible when an exemplar of the category of "body parts" appeared. The remainder of the stimuli were equally comprised of pairs of semantically related nouns (PRIME and TARGET) and unrelated pairs. Members of pairs appeared sequentially, and the order in which pairs were presented was randomized across subjects.

The tasks presented stimuli successively from randomized lists and required subjects to detect words belonging to a specified semantic category. In addition, nine of the patients were tested with the anomalous sentence task allowing direct comparison to our preceding companion article (McCarthy et al., 1995).

Task 1: words and nonwords. Figure 1 illustrates the word-list tasks. The stimuli were 440 letter strings, from which paired lists of 220 strings were randomly constructed. Five stimulus types were used in each list. (1) Fifty stimuli were orthographically illegal nonwords (NONwORDs) unpronounceable permutations of letters, mainly consonants (e.g., kldjgh). (2) Fifty were pronounceable nonwords (PSEUDO) that followed the rules of English phonology and orthography (e.g., glubbalt). (3) Fifty were words with grammatical function (FUNCTION)-prepositions, conjunctions, and articles (e.g., hence). (4) Fifty were concrete nouns with semantic content (CONTENT; e.g., truck). (5) The remaining 20 stimuli were exemplars (EXEMPLAR) of the category "fruits and vegetables" (e.g., cherry). Five randomized versions of the list were used.

The mean string length was equivalent for NONwORDs ( 5.4 characters), FUNCTION words (5.8 characters), and CONTENT words ( 5.3 characters). PSEUDO words were, on average, one character longer (6.4 characters). Despite using unusual grammatical connectives and common nouns, the frequency of FUNCTION words, determined from Kucera and Francis (1967), was significantly higher than for CONTENT words $(p<0.01)$.

Letter strings were presented individually (500 msec exposure) and successively on the center of a computer monitor with a stimulus-onset asynchrony (SOA) of 2.1-2.2 sec. Subjects were asked to press a button each time they detected an EXEMPLAR of the category of fruits and vegetables.

Task 2: semantic priming. Two lists of 220 concrete nouns were prepared. As before, 20 words were EXEMPLARs; this time of the category "body parts" (e.g., ankle). The remaining stimuli were composed of two types of word pairs. Half of the pairs contained semantically related words, with the first word of each pair designated the prime (PRIME; e.g., salt) and the second word the target (TARGET; e.g., pepper). The semantically related pairs were chosen so that either word primed the other equally well. The other half were unrelated word pairs.

Word pairs and category EXEMPLARS were randomly ordered, but targets always followed primes directly. Five randomized versions of the original two lists were used. Across subjects, the assignment of words within a prime-target pair was reversed so that a prime to one subject appeared as target to another subject. This manipulation counterbalanced word-frequency effects and word-order effects. The mean string length was 5.5 characters and did not differ significantly across stimulus types.

Stimulus display parameters were identical to those of Task 1. Subjects were asked to make a speeded button press response each time they detected an EXEMPLAR from the body parts category.

\section{Procedure}

All experimental runs were conducted in the patient's hospital room with the patient seated upright in bed and the room dimly ligh ed. A monitor was placed $05-1 \mathrm{~m}$ from the subject and tilted perperdicular to the direction of gaze. Each foveated character subtended $0.30-0.60^{\circ}$ of visual angle.

\section{Electrode placement and localization}

Methods for electrode placement were similar to those described in the preceding article (McCarthy et al., 1995). Recordings were made from posterior-temporal (PT) depth probes and subdural electrode strips. The PT probes were targeted to pass through the hippocampus along its longitudinal axis and to terminnt: .. the anterior temporal lobe near the amygdala. Probes were placed stereotaxically with MRI guidance (McCarthy et al., 1991). The probes were composed of a $1 \mathrm{~mm}$ diameter soft silastic core with 12 cylindrical nichrome electrodes (Adtech, Racine, WI) spaced equally from the distal tip. Strip electrodes were stainless steel discs $(2.2 \mathrm{~mm}$ diameter) with $1 \mathrm{~cm}$ interelectrode spacing. Strips were introduced subdurally through burr holes. The locations of electrodes were determined by their magnetic susceptibility artifact upon MRI images obtained the day after implant surgery.

Recordings were made from a total of 864 electrodes. One hundred thirty-eight were from PT probes (66 from the left hemisphere). The remainder were located mainly on the lateral and inferior surfaces of the temporal lobes. Recordings made from other brain regions were less systematic and will not be considered in this report. The Talairach coordinates of each electrode were calculated (Talairach and Tournoux, 1988).

\section{ERP recordings}

EEG was recorded from 32 or 64 electrodes simultaneously with a bandpass of $0.1-100 \mathrm{~Hz}$. The data were sampled continuously at $4 \mathrm{msec} /$ point throughout the entire duration of each experimental run. Codes 

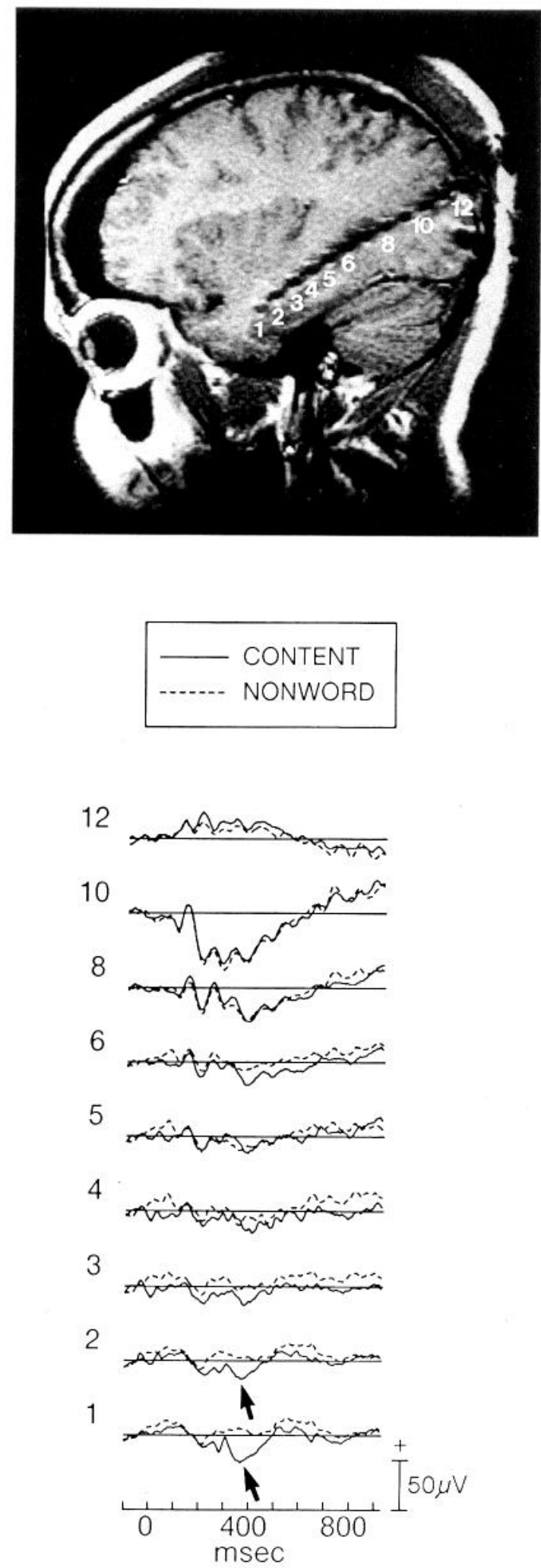

Figure 2. ERPs elicited by CONTENT words and NONWORDs along the right PT probe of subject ARS (left-handed), and MRI showing electrode locations. The large negative peak elicited by CONTENT words at the most distal contacts of the probe (AMTL N400) is indicated by black arrows. In this and all subsequent figures positive polarity is plotted upward. Unless otherwise noted, waveforms presented in figures come from right-handed patients. identifying the type and onset and type of each stimulus were incorporated into the data stream for offline analysis.

\section{Results \\ Behavioral performance}

The mean percentage of correct detections of fruit-and-vegetable EXEMPLARs for Task 1 (Words and Nonwords) was $77 \%$ and the mean reaction time was $718 \mathrm{msec}$. In Task 2 (Semantic Priming), subjects detected $72 \%$ of the body-part EXEMPLARS with a mean reaction time of $751 \mathrm{msec}$. Two-tailed $t$ tests indicated that the performance of the patients did not differ significantly across these two tasks. Reaction times for these patients were slower $(p<0.01)$ and less accurate $(p<0.01)$ than for a group of 15 normal volunteers who performed the same behavioral tasks (Nobre and McCarthy, 1994). No behavioral measures were obtained for the anomalous-sentence task, but informal debriefing confirmed that patients read the sentences.

\section{Posterior temporal depth probes}

Large focal negative field potentials were elicited by CONTENT words in both word-list tasks in all patients at the distal contacts of the PT probes. Figure 2 shows ERPs elicited by CONTENT and NONwORDS in Task 1 from the right PT probe in subject ARS. The ERPs elicited by CONTENT words and NONWORDS differed markedly at the most distal contacts (1-2) where CONTENT words elicited a large negative ERP at $400 \mathrm{msec}$ (black arrows).

This negative field potential was modulated in amplitude by task manipulations previously found to alter the amplitude of the scalp-recorded N400 (Nobre and McCarthy, 1994). For this reason and for consistency with the preceding article (McCarthy et al., 1995), we will use AMTL N400 to refer to this negative field potential. Figure 3 presents ERPs elicited by stimuli in the three tasks in subject CTR from the right PT electrode 1 located just anterior to the hippocampus. The AMTL N400 was equivalent in amplitude for CONTENT words, ANOMALOUS sentence endings, and PRIMES (approximately $50 \mu \mathrm{V}$ ). PSEUDO words elicited a smaller negative ERP than CONTENT words. FUNCTION and NONWORDS, however, did not elicit a sizeable negative ERP. Priming by sentence context (NORMAL sentence endings) greatly attenuated the amplitude of this negative potential. Priming by a semantically related word (TARGET) also attenuated this ERP, although to a lesser extent.

The consistency of these results was assessed by averaging ERPs across subjects. These across-subject ERPs were obtained by averaging ERPs from the electrode sites in each patient where the largest AMTL N400 was elicited by CONTENT words, independently of the data obtained for other stimulus types. Acrosssubject ERPs were then calculated for the sentence task $(n=9)$ and the semantic priming task $(n=5)$ using the same electrode sites. The across-subject ERPs and electrode sites are displayed in Figure 4. As before, CONTENT words, ANOMALOUS sentence endings, and PRIMEs elicited the largest AMTL N400s. For these stimuli, the average peak latency (approximately $400 \mathrm{msec}$ ) and the mean amplitude (approximately $30 \mu \mathrm{V}$ ) were equivalent. PSEUDO words elicited a smaller amplitude ERP, and FUNCTION and NONWORDS were smaller still. Priming by sentence context or by semantically related words attenuated the AMTL N400.

\section{Intracranial P300}

Large negative ERPs were elicited in the hippocampus by the EXEMPLARS in Tasks 1 and 2 . The polarity, magnitude, and latency of this large field potential were similar to those de- 

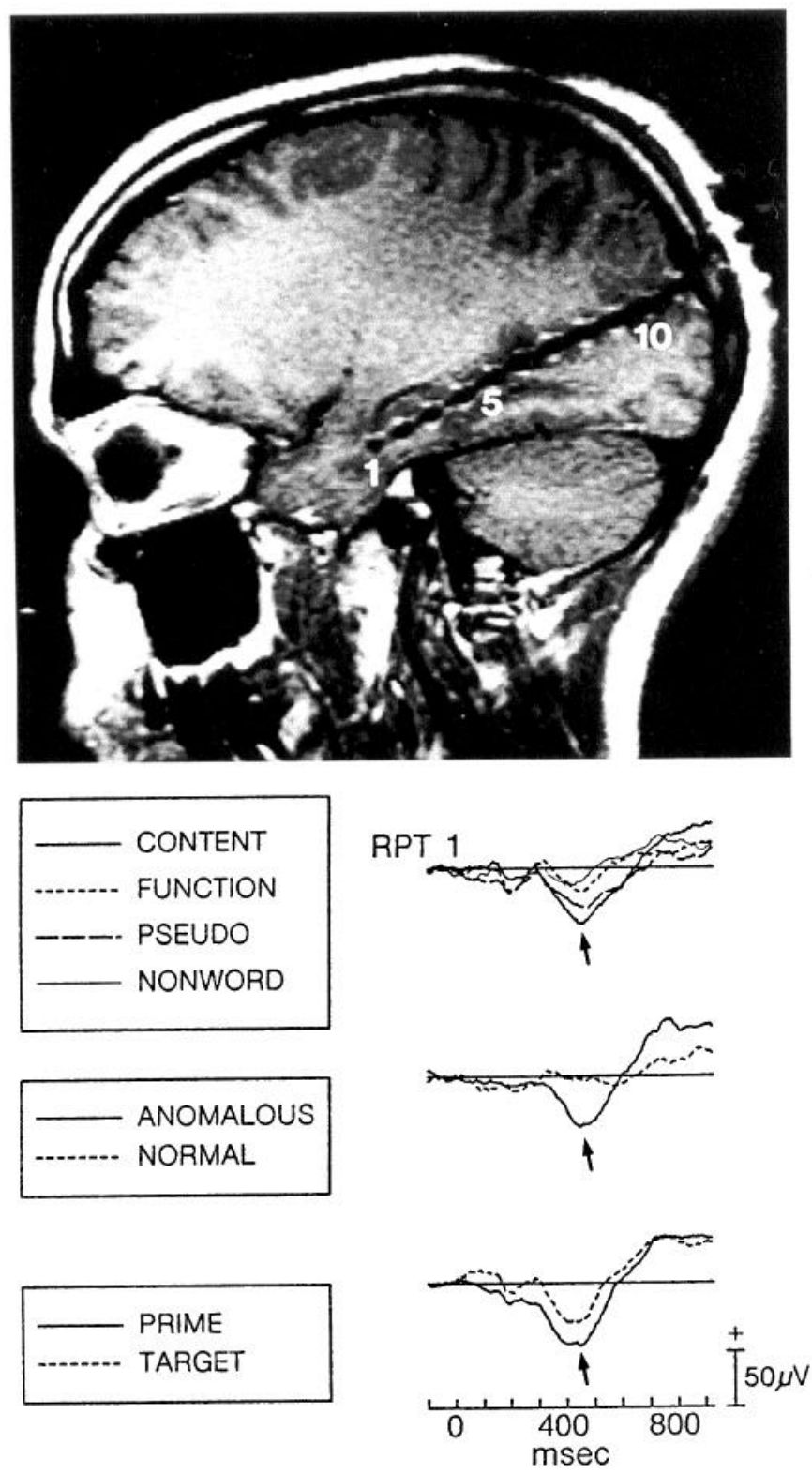

Figure 3. ERPs elicited by stimuli in the words-nonwords task (top), anomalous-sentence task (middle), and semantic-priming task (bottom) at the most distal contact of the left PT probe of subject CTR. The peak of the AMTL N400 is marked by a black arrow in each case. The MRI shows the electrode location of RPT 1 to be just anterior to the hippocampus. Electrode locations RPT 5 and RPT 10 pertain to ERPs in Figure 5.

scribed previously by us (McCarthy et al., 1989) and others (Halgren et al., 1980; Puce et al., 1989). In these prior studies, the hippocampal ERP was elicited by simple and complex stimuli of any modality (not restricted to language stimuli) and was largest for stimuli to which overt or covert responses were required. The task manipulations that affected this negative hippocampal ERP were similar to those that affected the positive scalp-recorded P300 ERP in the equivalent scalp studies (Nobre and McCarthy, 1994). The "hippocampal P300" and the language-sensitive AMTL N400 were often recorded from different contacts along the same PT probe. However, Figures 5 and 6 demonstrate that these two ERPs behaved differently with respect to the demands of Tasks 1 and 2, respectively. Figure 5
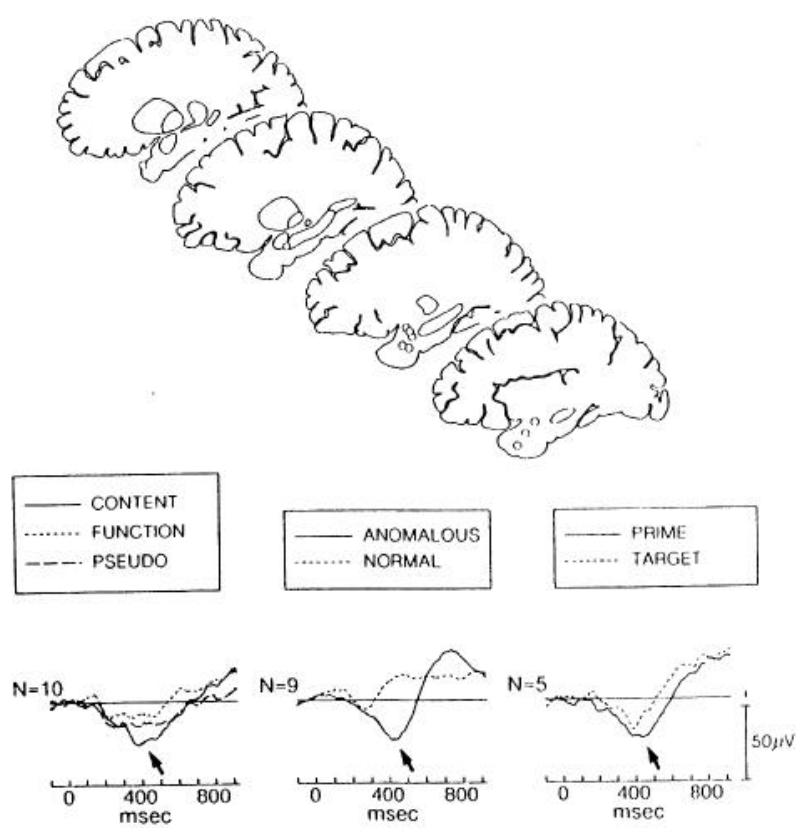

Figure 4. Below: grand-average ERPs elicited by stimuli in the wordsnonwords task (left), anomalous-sentence task (middle), and semanticpriming task (right). The electrode sites chosen were those showing the largest peak amplitude for the AMTL N400 in the words-nonwords task for each subject. Above: Talairach locations of electrodes contributing to the grand-averaged waveforms.

shows ERPs elicited by EXEMPLARS and CONTENT words at three electrodes from the right PT probe of subject CTR (electrode locations shown in Fig. 2). As can be seen, the EXEMPLARS elicited an AMTL N400 with similar amplitude to CONTENT words (electrode 1, small arrow). However, the hippocampal P300 elicited by EXEMPLARS (electrode 5, large arrow) was considerably larger and later than the AMTL N400.

ERPs elicited by EXEMPLARS and PRIMES at three electrodes from the left PT probe of subject KSR are shown in Figure 6. LPT 6 was located in the hippocampus where a large negative ERP $(200 \mu \mathrm{V})$ was elicited by EXEMPLARS (large arrow) at approximately $600 \mathrm{msec}$. PRIMES elicited a substantially smaller hippocampal ERP. At the more distal electrode 2, located anterior to the hippocampus in the white matter lateral to the amygdala, EXEMPLARS and PRIMES elicited AMTL N400s (small arrow) of equivalent amplitude $(75 \mu \mathrm{V})$.

\section{Inferior temporal cortical ERPS}

In eight patients, a large positive ERP was recorded on the inferior surface of the anterior temporal lobe coincidentally with an AMTL N400. These positive ERPs were focally distributed, usually recorded from only one or two electrodes of a subdural strip. They were affected similarly as AMTL N400 with respect to task manipulations as illustrated in Figures 7 and 8.

Figure 7 presents ERPs associated with CONTENT and FUNCTION words recorded from the left PT probe and from the underlying inferior temporal surface in patient ERI. At LPT 3, located in the amygdala, a focal AMTL N400 was elicited by CONTENT words (black arrow) with an amplitude of $45 \mu \mathrm{V}$ amplitude. Electrodes 3 and 4 of the subdural LAT strip were located on the cortical surface just inferior to LPT 3 and straddling the collateral sulcus. The cortical surface electrodes recorded a focal positive ERP that was also largest for CONTENT words (open 

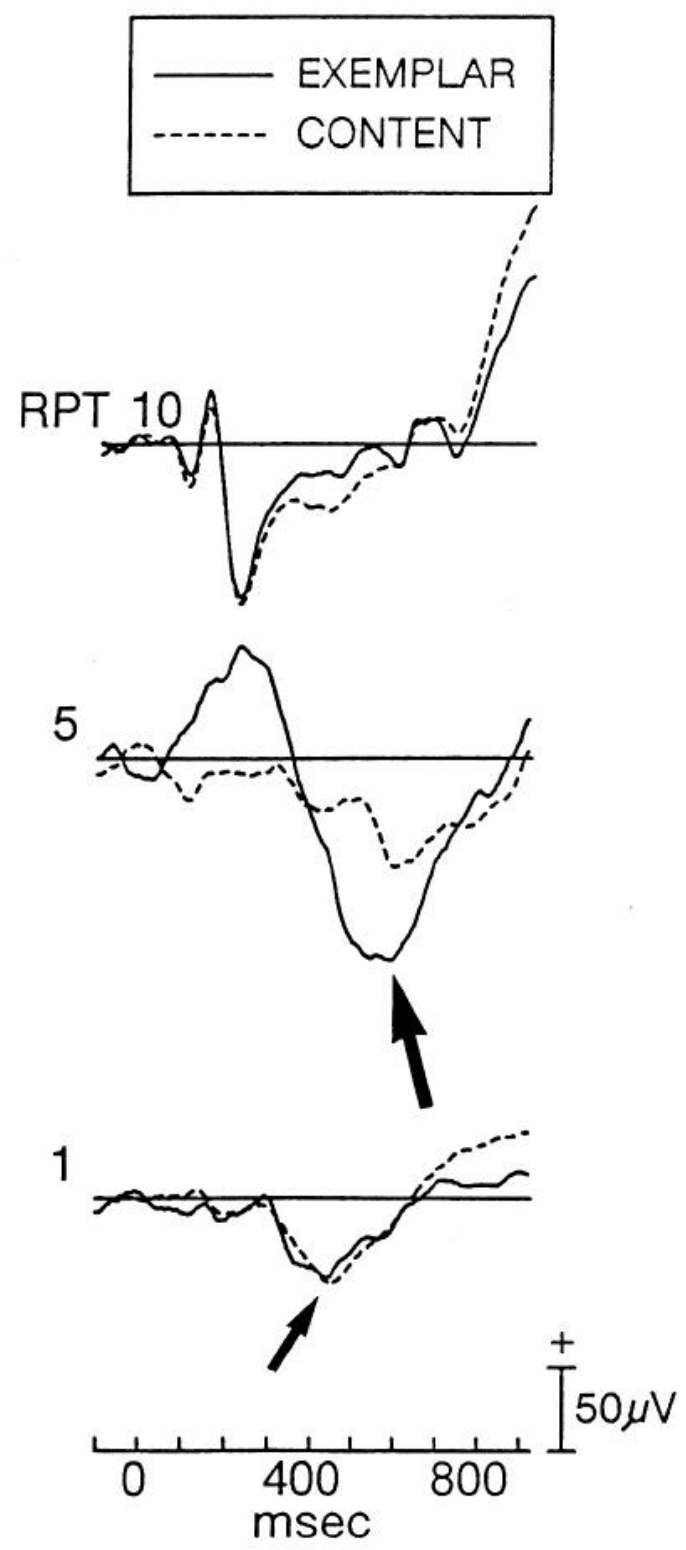

Figure 5. ERPs elicited by EXEMPLARS and CONTENT words (wordsnonwords task) at three electrodes of the right PT probe for subject CTR. The AMTL N400 is marked by a small black arrow, and the hippocampal P300 is marked by a large black arrow. Electrode locations are shown in Figure 3. Electrode RPT 1 was located just anterior to the hippocampus, electrode RPT 5 was in the hippocampus, and electrode RPT 10 was in occipital cortex.

arrows). The positive ERP had a similar latency (approximately $400 \mathrm{msec}$ ) and somewhat larger amplitude (approximately 65 $\mu \mathrm{V}$ at LAT3) than the AMTL N400 at LPT 3. Neighboring electrodes LAT2 and LAT6 did not exhibit large positive ERPs.

Figure 8 shows ERPs elicited by PRIMES and TARGETS recorded

Figure 6. ERPs elicited by EXEMPLARS and PRIMES (semantic priming task) at three electrodes of the left PT probe for subject KSR. The AMTL N400 is marked by a small black arrow, and the hippocampal P300 is marked by a large black arrow. Electrode locations are shown on the MRI. Electrode LPT 1 was anterior to the hippocampus in the white matter lateral to the amygdala, electrode LPT 6 was in the hippocampus, and electrode LPT 11 was in occipital cortex.

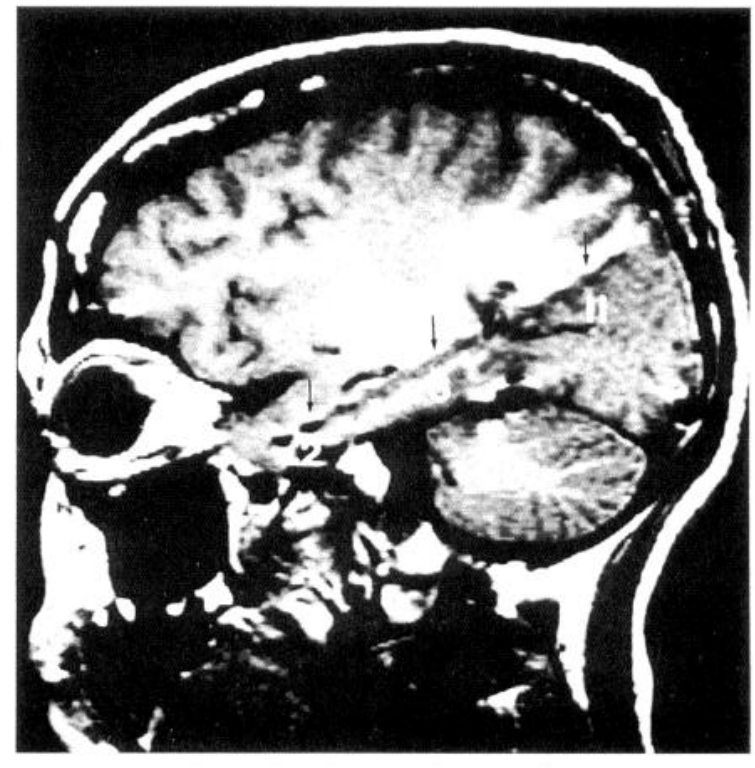

\section{EXEMPLAR} PRIME

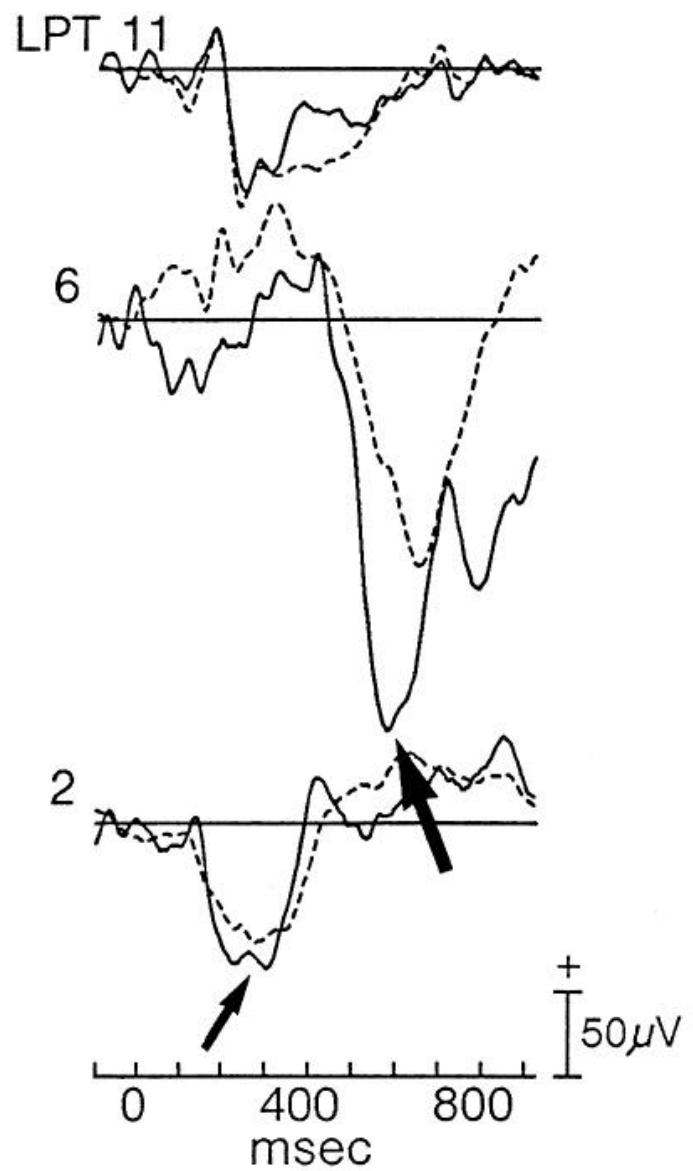



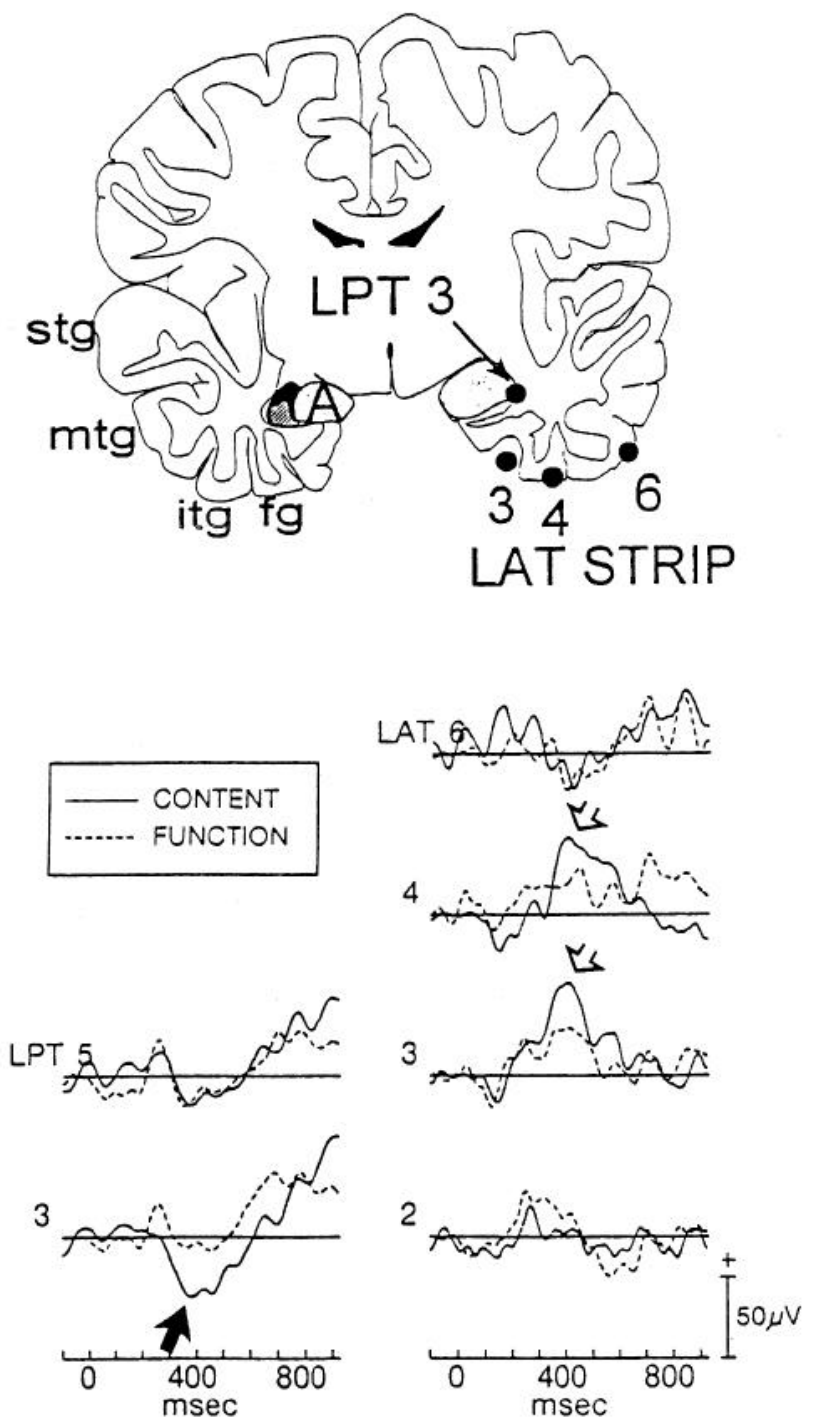

Figure 7. ERPs elicited by CONTENT words and FUNCTION words (wordsnonwords task) at two electrodes of the left PT probe and four electrode sites of the underlying left subdural strip LAT. The MRI tracing shows the location of the left PT electrode 3, and electrodes 3, 4, and 6 of the subdural strip LAT. The AMTL N400 recorded from LPT 3 in the amygdala is marked by the solid black arrow. The positive field potential recorded from the underlying electrodes LAT 3 and 4, straddling the collateral sulcus, is marked by an open arrow.

from the right PT probe and the inferior temporal surface in patient RSR. RPT 4 and 5 within the hippocampus recorded a biphasic ERP complex consisting of a large negative ERP that peaked at $800 \mathrm{msec}$ (large black arrows) preceded by a positive ERP at 500 msec (curved arrow). The negative hippocampal ERP was larger for PRIMES than TARGETS, but the preceding positive ERP was equivalent for both stimulus types. At RPT 1 in the amygdala, an AMTL N400 $(45 \mu \mathrm{V})$ was recorded. The AMTL N400 was greatly attenuated for the semantically primed TARGETS. The RMT subdural strip was located just inferior to RPT 1 along the anterior inferior surface of the temporal lobe. RMT2, located medial to the collateral sulcus, displayed a large focal positive ERP that was also diminished by semantic priming (open arrow). The positive ERP had a similar latency (430 msec) and amplitude $(50 \mu \mathrm{V})$ as the AMTL N400 at RPT 1.

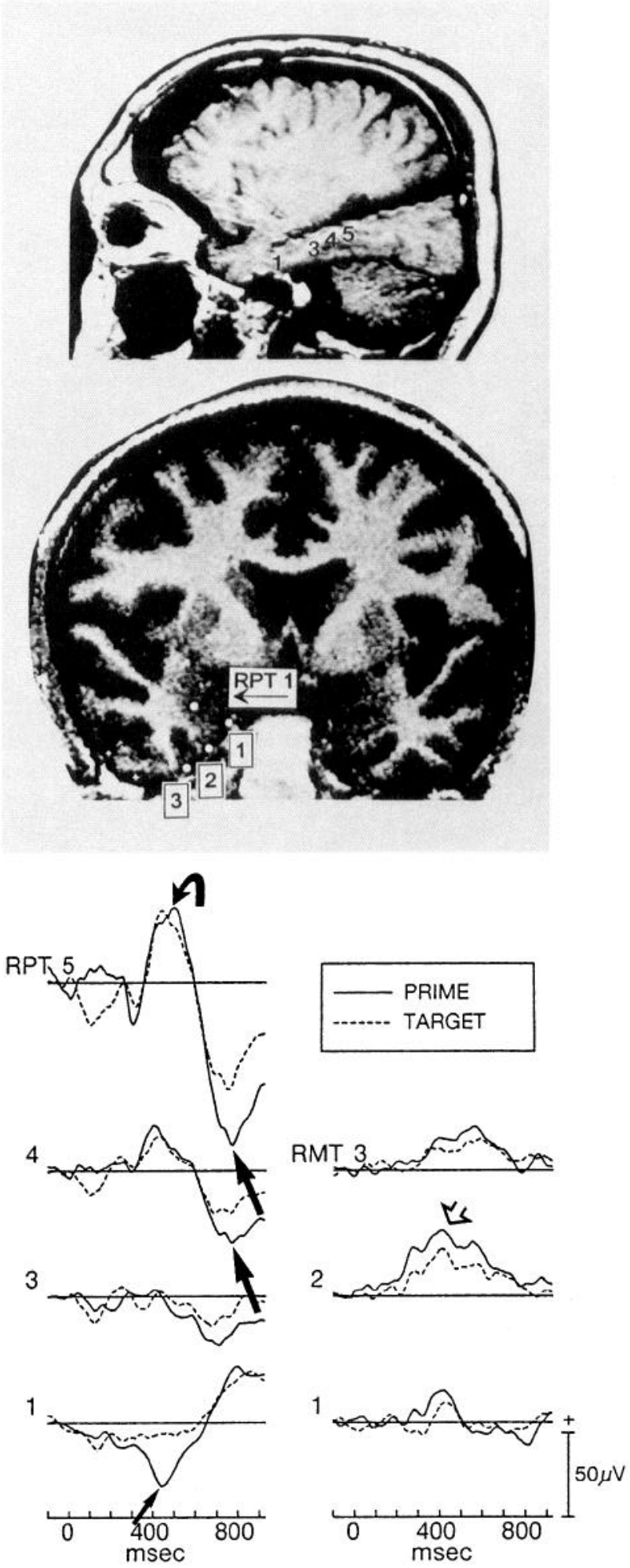

Figure 8. ERPs elicited by PRIMES and TARGETS (semantic priming task) at four electrodes of the right PT probe and three electrode sites of the underlying left subdural strip RMT. The MRIs show the location of the right PT electrodes (top), and the locations of the subdural-strip electrodes relative to RPT 1 (bottom). The AMTL N400 recorded from RPT 1 in the amygdala is marked by the small solid black arrow. The hippocampal P300, recorded at electrodes RPT 4 and 5 within the hippocampus, is marked by large black arrows. The curved black arrow marks the positive potential that preceded the hippocampal P300 at RPT 5. The positive ERP recorded from the subdural electrode RMT 2 medial to the collateral sulcus is marked by an open arrow. 


\section{Discussion}

We have demonstrated that isolated content words elicit an AMTL negative field potential with the same latency, amplitude, and intracranial distribution as the AMTL N400 elicited by anomalous sentence-ending words described in the preceding report (McCarthy et al., in press). Furthermore the AMTL N400 was shown to be sensitive to orthography, word-type, and semantic priming. Orthographically illegal and unpronounceable NoNwORDs did not elicit the AMTL N400 (see Figs. 2, 3). FUNCTION words (grammatical connectives), devoid of semantic representation and visual imagery, elicited little AMTL N400 activity (see Figs. 3, 4, 7). AMTL N400s were reliably elicited by CONTENT words in sentences and in lists. The content words used here were concrete nouns with high visual imageability. Preexposure to a semantically related word attenuated the AMTL $\mathrm{N} 400$ as did priming by sentence context (see Figs. 3, 4, 8).

The role of the anterior temporal lobe in language-related processing is not clearly understood. The anterior temporal lobe receives highly processed neural information from polymodal cortical areas (Swanson et al., 1987). Surgical resection of anterior and medial left temporal lobe, including the hippocampus, can result in verbal memory deficits (Milner, 1974). Patients with damage to the neocortex of the inferior surface of the temporal lobe can suffer impairment in naming common visual objects, although their general knowledge, vision, and language remain largely intact. These associative visual agnosias have been interpreted as disorders of the highest levels of visual processing (see Farah, 1990; Mesulam, 1994). The anterior and middle portions of the temporal lobe bilaterally have been proposed to store conceptual representations of objects (McCarthy and Warrington, 1986; Warrington and McCarthy, 1987). Damasio and colleagues have proposed that the left anterior temporal neocortex mediates between the storage system of conceptual representations and other language regions (Damasio and Damasio, 1992). The anterior temporal neocortex could serve to label concepts such as objects, scenes, faces with words.

Neuroimaging studies have also supported the involvement of the anterior left temporal lobe in language-related processing. Activation of the left inferior temporal lobe was observed in tasks requiring the generation of mental images from verbal stimuli (Mazziotta, 1984; Goldenberg et al., 1987). Verbal comprehension tasks involving listening to texts, anomalous sentences, or sentences with pseudowords have also been shown to engage the anterior temporal lobes (Mazoyer et al., 1993).

The functional role of the neural processes refiected by the AMTL N400 is suggested by its sensitivity to priming and to word type. Like Smith et al. (1986), we favor a mnemonic role; however, this allows for many alternative hypotheses. Two possibilities seem likely. In the first, the AMTL N400 reflects the activity in a network of semantic representations associated with the eliciting word. Thus, content words elicit $\triangle \mathrm{MTL}$ N400s because they have rich semantic representations; function words do not elicit AMTL N400s because they have impoverished representations; and orthographically illegal nonwords do not elicit AMTL N400 because they have no representations. Priming (by sentence context or by semantic associates) attenuates AMTL N400 by preactivating representations directly or by a passive process like spreading activation (Collins and Loftus, 1975). Such an interpretation is also consistent with Smith et al.'s finding that repetition diminishes the amplitude of the AMTL N400. The AMTL N400s elicited by pseudowords may reflect partial activation of the representations of orthographically or phonologically similar real words.

In the second possibility, the AMTL N400 is related to the postlexical integration of stimuli with the ongoing context (Rugg and Doyle, 1992; Holcomb, 1993) or with the association of stimuli with verbal labels (Damasio and Damasio, 1992). In this formulation, the AMTL N400 either reflects the neural processes responsible for associating the present stimulus with the context or meaning developed by preceding stimuli, or some error signal indicating that a violation of context has occurred and further processing is required. When a stimulus is delivered into a compatible context (such as normal sentence endings and primed words), little new integration or association is required and the AMTL N400 is consequently small. Anomalous sentence endings and content words presented after unrelated words require integration and, therefore, elicit AMTL N400s. Function words and orthographically illegal nonwords, which also elicit little AMTL N400, are presumably identified as such earlier than 400 msec and, therefore, do not elicit this field potential because they are excluded from this depth of processing. Pseudowords elicit AMTL N400 because they obey the rules of English orthography and phonology and, therefore, could be real words. Such an associative process may be how previously unknown words acquire their meaning.

The integrative/associative hypothesis avoids the possible objection that AMTL N400 occurs too late to be related to the activation of a semantic representation, although we caution that the peak amplitude of a physiological measure may not absolutely reflect when the critical neural events occurred. The similar amplitude of the AMTL N400 across content words and anomalous sentence endings in the present study, and in our study of scalp-recorded N400 (Nobre and McCarthy, 1994), however, is inconsistent with such hypothesis. One might expect that the context developed by a sentence would be greater (and, hence, require more integration) than the context developed by a scries of unrelated words. Context diminishes the amplitude of N400 more than lack of context enhances it.

\section{Relationship to scalp N400}

The results strongly suggest that the AMTL N400 is a contributing generator of the scalp-recorded $\mathrm{N} 400$ because it responds similarly to the same experimental manipulations. As in the corresponding scalp study (Nobre and McCarthy, 1994), the peak latencies and amplitudes were similar in the sentence task and in the word-list tasks. The peak latencies observed intracranially, around $350-450 \mathrm{msec}$, were comparable to the peak latencies for the maximal negative ERP deflections recorded from the scalp.

Analysis of N400 scalp distribution (Nobre and McCarthy, 1994) demonstrated that several ERP components with overlapping spatial distributions occurred within the N400 time window (250-500 $\mathrm{msec})$. The latest and dominant negativepolarity component (N400) had a broad distribution over the central and centro-posterior scalp that is consistent with a deep source (Kutas et al., 1988a,b; Nobre and McCarthy, 1994; McCarthy et al., in press) such as observed for the AMTL N400.

\section{Neural source of AMTL ERP}

The neocortex in the region of the collateral sulcus and anterior fusiform gyrus is the likely neural generator of the AMTL N400 due to the sharp voltage gradients in this region. Focal positive potentials were recorded from electrodes on the fusiform gyrus 
in close proximity to the depth electrodes of the PT probes that recorded focal negative ERPs. The positive ERPs from the inferior surface had comparable amplitudes to the corresponding negalive AMTL N400s, suggesting that these electrode sites spanned the active neural tissue. Furthermore, both positive and negative ERPs were similarly affected by word type (Fig. 7) and semantic priming (Fig. 8).

As in the previous study, hippocampal ERPs were elicited by stimuli in the word list tasks. Large negative ERPs were elicited by EXEMPLARS of the target category, and were similar in latency to scalp P300s elicited in equivalent tasks (Nobre and McCarthy, 1994). Similar hippocampal negative ERPs have been obtained in other categorization tasks using nonverbal stimuli (e.g., McCarthy et al., 1989). In some subjects, a positive hippocampal ERP preceded the negative ERP forming a biphasic complex (Figs. 5, 8). Since the positive hippocampal ERP temporally overlapped the AMTL N400, it is possible that part or all of the AMTL N400 is generated by the hippocampus. However, as in the preceding study (McCarthy et al., 1995), the variable relationship between the peak latencies of this hippocampal positive ERP and the AMTL N400 across subjects suggested that they were generated by different neuronal populations. In addition, semantic priming functionally dissociated the AMTL N400 and the hippocampal-positive ERP in that AMTL N400 was attenuated by priming (Fig. 8), while the coincident-positive ERP in the hippocampus was not.

The relationship between scalp N400s and P300s has been controversial. These two ERPs often overlap temporally posing interpretational difficulties (see Bentin et al., 1985; Kutas and Hillyard, 1989; Curran et al., 1993; Nobre and McCarthy, 1994). Our results suggest that the AMTL N400 and later hippocampal field potentials (which have been associated with the scalp-recorded P300) have different neural generators. To the extent that these intracranial field potentials are reflected in the scalprecorded N400 and P300, these scalp ERPs are physiologically distinct. Nevertheless, it is possible that the neural processes reflected by these two field potentials are functionally interrelated. In some instances, modulation of the hippocampal negative ERP was similar to the preceding AMTL N400 (see Fig. 8). However, the hippocampal-negative ERP was also sensitive to the response requirements of the tasks. EXEMPLARS, which required an overt response, elicited a much larger hippocampal ERP than any other stimuli. The AMTL N400 amplitude for EXEMPLARS, however, was equivalent to that of unprimed CONTENT words (see Figs. 5, 6). The functional dissociations between hippocampal ERPs and the AMTL ERP by response requirement argues strongly that these two potentials reflect distinct neural and functional processes.

\section{References}

Bentin S (1987) Event-related potentials, semantic processes, and expectancy factors in word recognition. Brain Language 31:308-327.

Bentin S, McCarthy G, Wood CC (1985) Event-related potentials, lexical decision, and semantic priming. Electroencephalogr Clin Neurophysiol 60:343-355.

Besson M, Macar F (1986) Visual and auditory event-related potentials elicited by linguistic and non-linguistic incongruities. Neurosci Lett 63:109-114.

Besson M, Macar F (1987) An event-related potential analysis of incongruity in music and other non-linguistic contexts. Psychophysiology 24: i 4-25.

Boddy J (1986) Event-related potentials in chronometric analysis of primed word recognition with different stimulus onset asynchronies. Psychophysiology 23:232-245.
Collins AM, Loftus, EF (1975) A spreading activation theory of semantic processing. Psychol Rev 82:407-428.

Curran T, Tucker DM, Kutas M, Posner MI (1993) Topography of the N400: brain electrical activity reflecting semantic expectancy. Electroencephalogr Clin Neurophysiol 88:188-209.

Damasio AR, Damasio H (1992) Brain and language. Sci Am 267: 89-95.

Farah MJ (1990) Visual agnosia: disorders of object recognition and what they tell us about normal vision. Cambridge: MIT Press.

Fischler I, Raney GE (1989) Language by eye: behavioral, autonomic, and cortical approaches to reading. In: Handbook of cognitive psychology: central and autonomic nervous system (Jennings JR, Coles MGH, eds). Ncw York: Wilcy.

Fischler I, Childers DG, Achariyapaopan T, Perry NW Jr (1985) Brain potentials during sentence verification: automatic aspects of comprehension. Biol Psychol 21:83-106.

Goldenberg G, Podreka I, Steiner M, Willmes K (1987) Patterns of regional cerebral blood flow related to memorizing of high and low imagery words: an emission computer tomographic study. Neuropsychologia 25:473-485.

Halgren E, Squires NK, Wilson CL, Rohrbaugh JW, Babb TL, Crandall PH (1980) Endogenous potentials generated in the human hippocampal formation and amygdala by infrequent events. Science 210 : 803-805.

Holcomb PJ (1986) ERP correlates of semantic facilitation. In: Electroencephalography and clinical neurophysiology, suppl 38, Cerebral psychophysiology: studies in cvent-related potentials (McCallum WC, Zappoli R, Denoth F, eds), pp 320-322. Amsterdam: Elsevier.

Holcomb PJ (1988) Automatic and attentional processing: an eventrelated brain potential analysis of semantic priming. Brain Lang 35 : 66-85.

Holcomb PJ (1993) Semantic priming and stimulus degradation: implications for the role of the N400 in language processing. Psychophysiology 30:47-61.

Holcomb PJ, Neville HJ (1991) Natural speech processing: an analysis using event-related brain potentials. Psychobiology 19:286-300.

Kounios J, Holcomb PJ (1992) Structure and process in semantic memory (II): evidence from event-related potentials and reaction times. J Exp Psychol [Gen] 121:459-479.

Kucera H, Francis WN (1967) Computational analysis of present day American English. Providence, RI: Brown.

Kutas M, Hillyard SA (1980) Event-related brain potentials to semantically inappropriate and surprisingly large words. Biol Psychol 11:99-116.

Kutas M, Hillyard SA (1989) An electrophysiological probe of incidental semantic association. J Cogn Neurosci 1:38-49.

Kutas M, Van Petten C (1988) Event-related potential studies of language. In: Advances in psychophysiology (Ackles PJ, Jennings JR, Coles MGH, eds), pp 139-187. Greenwich: JAI.

Kutas M, Lindamood T, Hillyard SA (1984) Word expectancy and event-related brain potentials during sentence processing. In: Preparatory states and processes (Kornblum S, Requin J, eds), pp 217328. Hillsdale, NJ: Erlbaum.

Kutas M, Neville HJ, Holcomb PJ (1987) A preliminary comparison of the $\mathrm{N} 400$ response to scmantic anomalies during reading, listening and singing. In: Electroencephalography and clinical neurophysiology, Suppl 39, The London symposia (Erlingson RJ, Murray NMF, Halliday AM, eds), pp 325-330. Amsterdam: Elsevier.

Kutas M, Hillyard SA, Gazzaniga MS (1988a) Processing of semantic anomaly by right and left hemispheres of commissurotomy patients. Brain 111:553-576.

Kutas M, Van Petten C, Besson M (1988b) Event-related potential asymmetries during the reading of sentences. Electroencephalogr Clin Neurophysiol 69:218-233.

Lencz T, McCarthy G, Bronen RA, Scott TM, Inserni JA, Sass KJ, Novelli RA, Kim JH, Spencer DD (1992) Quantitative magnetic resonance imaging in temporal lobe epilepsy: relationship to neuropathology and neuropsychological function. Ann Neurol 31:629-637.

Mazoyer BM, Tzourio N, Frak N, Murayama N, Levrier O, Salamon G, Dehaene S, Cohen I, Mehler J (1993) The cortical representation of speech. J Cogn Neurosci 5:467-479.

Mazziotta JC (1984) Tomographic mapping of human cerebral metabolism: subcortical responses to auditory and visual stimulation. Neurology 34:825-828.

McCallum WC, Farmer SF, Pocock PV (1984) The effects of physical 
and semantic incongruities on auditory event-related potentials. Electroencephalogr Clin Neurophysiol 59:477-488.

McCarthy G, Blamire AM, Rothman DL, Gruetter R, Shulman RG (1993) Echo-planar MRI studies of frontal cortex activation during word generation in humans. Proc Natl Acad Sci USA 90:4952-4956.

McCarthy G, Nobre AC (1993) Modulation of semantic processing by spatial selective attention. Electroencephalogr Clin Neurophysiol 88:210-219.

McCarthy G, Nobre AC, Bentin S, Spencer DD (1995) Languagerclatcd ficld potentials in the antcrior-medial temporal lobe: I. Intracranial distribution and neural generators. J Neurosci 15:1080-1089.

McCarthy G, Spencer DD, Riker RJ (1991) The stereotaxic placement of depth electrodes in epilepsy. In: Epilepsy surgery (Luders H, ed), pp 385-393. New York: Raven.

McCarthy G, Wood CC (1984) Intracranially recorded event-related potentials during sentence processing. Soc Neurosci Abstr 10:847.

McCarthy G, Wood CC, Bentin S (1985) Human intracranial ERPs during lexical decision. Soc Neurosci Abstr 11:880.

McCarthy G, Wood CC, Williamson PD, Spencer DD (1989) Taskdependent field potentials in human hippocampal formation. J Neurosci 9:4253-4268.

McCarthy R, Warrington EK (1986) Visual associative agnosia: a clinico-anatomical study of a single case. J Neurol, Neurosurg Psychiatry 49:1233-1240.

Mesulam MM (1990) Large-scale neurocognitive networks and distributed processing for attention, language, and memory. Ann Neurol 28:597-613.

Mesulam MM (1994) Higher visual functions of the cerebral cortex and their disruption in clinical practise. In: Principles and practise of opthamology: the Harvard system (Alpert DM, Jakobiec SA, eds), pp 2640-2653. Philadelphia: Saunders.

Milner B (1974) The neurosciences: Third study program (Schmitt FO, Norden FG, eds), pp 75-89. Cambridge, MA: MIT Press.
Nobre AC, McCarthy G (1994) Language-related ERPs: modulation by word type and semantic priming. J Cogn Neurosci 6: in press.

Paller K, McCarthy G, Wood CC (1992) Event-related potentials elicited by deviant endings to melodies. Psychophysiology 29:202-206.

Puce A, Andrewes DG, Berkovic SF, Bladin PF (1989) Visual recognition memory: neurophysiological evidence for the role of temporal white matter in man. Brain 114:1647-1666.

Rugg MD (1985) The effects of semantic priming and word repetition on event-related potentials. Psychophysiology 22:642-647.

Rugg MD, Doyle MC (1992) Event-related potentials and stimulus repetition in direct and indirect tests of memory. In: Cognitive electrophysiology (Heinze H, Munte T, Mangun R, eds). Boston: Birkhauser.

Rugg MD, Nagy ME (1987) Lexical contribution to nonword-repetition effects: evidence from event-related potentials. Mem Cogn 15: 473-481.

Smith ME, Halgren E (1989) Dissociation of recognition memory components following temporal lobe lesions. J Exp Psychol [Hum Learn] 15:50-60.

Smith ME, Stapleton JM, Halgren E (1986) Human medial temporal lobe potentials evoked in memory and language tasks. Electroencephalogr Clin Neurophysiol 63:145-149.

Swanson LW, Kohler C, Bjorklund A (1987) The limbic region: the scptohippocampal system. In: Handbook of chemical neuroanatomy (Bjorklund A, Hokfelt T, Swanson LW, eds), pp 125-277. Amsterdam: Elsevier.

Talairach J, Tournoux P (1988) Co-planar stereotaxic atlas of the human brain. New York: Thieme.

Van Petten C, Kutas M (1991) Influences of semantic and syntactic context on open- and closed-class words. Mem Cogn 19:95-112.

Warrington EK, McCarthy R (1987) Categories of knowledge: further fractionations and an attempted integration. Brain 110:1273-1296. 